\title{
BLOCKCHAIN TECHNOLOGY IN Agriculture: A Case STUdy OF BLOCKCHAIN START-UP COMPANIES
}

\author{
Chandra Sekhar Bhusal \\ School of Engineering, Information Technology and \\ Physical Sciences Federation University, Australia
}

\begin{abstract}
Agriculture is one of the areas where blockchain technology could bring a revolution by solving the existing problem of Agri-product fraud, its traceability, price manipulation, and lack of customer trust in the product. This paper aims to demonstrate the potential application of blockchain technology in the agriculture industry and how it could address the existing issues by surveying the existing paper and following case studies of the blockchain start-up companies. Blockchain technology shows a promising approach to fostering a safer, better, more sustainable, and dependable agri-foods system in the future. While the application of blockchain in agriculture is in the initial phase and faces various issues like cost of implementation, privacy, security scalability, performance, and infancy, it can bring a revolution in the agriculture industry.
\end{abstract}

\section{KEYWORDS}

Blockchain Technology, Trust, Transparency, Security, Traceability.

\section{INTRODUCTION}

Agribusiness refers to any business associated with farming and farming-related commercial activities[1]. It is highly multi-stakeholder and distributed, involving many different actors, such as farmers, shipping companies, wholesalers and retailers, distributors, and groceries[2]. In existing agribusiness the all the information either resides on paper or private servers and databases of the trusted third parties. Such structure results in an increase of cost to access the data, subject to fraud, corruption, or error that lead to financial losses as well as chances of product counterfeit. The existing agriculture structure lacks (1) the traceability of the product,(2) the security of product information,(3) the trust among the partners in the supply chain, and (4) the trust and confidence of customers in the product's quality[3]. Agriculture is known to be the least digitised industry that missed out to take advantages of the internet, due to lack of connectivity. To address the problems of tracing, food safety, and building trust among the stakeholders in the supply chain some initiatives have been taken in recent years with the use of Information and Communication Technology(ICT). The use of ICT increases the effectiveness and efficiency of data acquisition, storage, analysis, and use in agriculture, enabling all stakeholders to easily get updated information and thus make more effective decisions in their daily farming activities[4]. The main aim was to track and monitor the entire life cycle of food production, including growth, processing, transportation, storage, and selling, which involves a large range of untrusted business parties. But the parties operating the ICT are not fair enough in data collection and its use where they are motivated in using the data in the favour of their interest[5]. In addition, legacy ICT has centralized management, centralized databases for storing agribusiness data, with a high risk of single-point failure, cyber-attack, asynchronous inaccuracy, 
censorship, data corruption, and scientific misconduct[6]. So here comes blockchain technology as an effective solution that addresses the existing problems, making it difficult or impossible to manipulate the data by distributing the data management capabilities to a large number of distributed parties.

Blockchain in general is a distributed database technology that maintains the constantly increasing list of data records that are verified by all the participating nodes in the network [7],[8],[9]. Data records are stored in the blocks and each block is linked together forming the chain. Data within the block are immutable and all the participating nodes within a blockchain network have access to the entire distributed database which eliminates the single node taking control of the data records. Instead of information routed through a central node, each participating nodes store a copy of the data records and forwards to all the remaining nodes within a network enhancing trust and transparency[9]. The working mechanism of the blockchain technology and can be explained as [8],[10],[3],[11]: In the first step the transaction is requested and the block is created. In the next step, the newly created block is broadcasted to all the nodes in the network. All the nodes in the network reach a consensus about the requested transaction and get verified in the next step. Once the transaction gets verified, the block is added to the existing blocks with a new block of data in the final step. Blockchain with its unique characteristics is gaining popularity in many sectors including agriculture. Table 1. highlights important features of blockchain technology.

Blockchain technology has been applied successfully in the financial sector especially in banking and cryptocurrency. Due to its distinctive features, it has been proven a perfect solution in many areas where there is a need for trust and transparency. Supply chain, voting, healthcare, energy market, real estate, public service, personal identity security, music royalty tracking, and many more are some of the areas where blockchain technology has been successfully implemented [2],[10],[12],[13]. Its application in agribusiness is gradually increasing in recent years that is motivated by the Agri-product fraud that leads to adverse effects on the health of consumers. The main usage of blockchain technology in Agribusinesses focused on product traceability that involves capturing, storing, and transmitting product information in all stages of the Agri-supply chain. Such information enables (1) building trust and transparency among different actors in agri-business, (2) check product's safety and quality, and (3) building customer's confidence and trust[13]. Some of the promising benefits of blockchain adoption in agribusiness can be outlined as:[4],[2],[13]. Increase Trust: Blockchain due to its distributed nature and cryptography, the necessity of any central authority for information storage and security is eliminated hence restoring trust between producer and consumers. Improve Traceability: The decentralized ledger that records each stage product's information enables to connect inputs from suppliers, producers, buyers, regulators who are relatively apart from each other, help to enhance the traceability of the Agri-products. Improve product safety and quality: Product information is recorded at every stage of the supply chain thus allowing all parties to ensure good hygienic conditions, early identification of any contamination, risks, and frauds in products. The benefit to small farmers: Small farmers can get a fair market price as they can track the status of the product and changing market price using blockchain technology without depending on the intermediates/middlemen. Improve consumer trust: Consumers can access all the product's information at every stage of the supply chain hence increasing confidence and trust in the consumed product. This objective of the paper is to highlight and analyse how blockchain technology is being implemented in agriculture in real world and how it could address the existing unsolved problems of agribusiness.

The rest of the paper is structured as Section "Literature Review", presents a brief overview of the background study, past works and tries to identify the need and usage of BCT in the agriculture sector. Section "Blockchain Approaches in the Agriculture" presents the companies we used as case studies and their approaches to implementing blockchain technology in the agri- 
food industry. Section "Discussion," provides a discussion about the state of practice and the current open issues related to blockchain use in the agri-food sector. Section "Conclusion" concludes the paper.

Table 1. Features of Blockchain Technology

\begin{tabular}{|l|l|l|}
\hline \multicolumn{1}{|c|}{ Reference } & \multicolumn{1}{|c|}{ Features } & \multicolumn{1}{c|}{ Explanation } \\
\hline$[10][12][13][14][19]$ & Decentralization & $\begin{array}{l}\text { There is no single point of control and failure where } \\
\text { information is stored and shared throughout the } \\
\text { network. }\end{array}$ \\
\hline$[10][12][13][14]$ & Immutability & Data once stored cannot be deleted or altered \\
\hline$[14][19]$ & $\begin{array}{l}\text { Peer } \\
\text { Verification }\end{array}$ & $\begin{array}{l}\text { Verification of each transaction via consensus } \\
\text { among the peers. }\end{array}$ \\
\hline$[14]$ & Cryptography & Provides security of transaction and data \\
\hline$[14][19]$ & Transparency & $\begin{array}{l}\text { Data is accessible among all the peers in the } \\
\text { network providing transparency }\end{array}$ \\
\hline$[13][14]$ & Anonymity & $\begin{array}{l}\text { Every participant communicate by generated virtual } \\
\text { identity code that cover the real identity of the } \\
\text { participant. }\end{array}$ \\
\hline
\end{tabular}

\section{LiterATURE REVIEW}

\subsection{Blockchain in Supply Chain Management}

[2] examines the influence of blockchain technology on agriculture and the food supply chain by presenting the current projects and initiatives that use blockchain technology for addressing the issues of the current agricultural supply chain. The paper overall discusses the broader implications, difficulties, and possibilities of such initiatives while taking a critical look at their maturity. The paper finds that blockchain technology would be a promising technology for a transparent agricultural supply chain. The blockchain-enabled supply chain can record the necessary information at every stage of the supply chain (Provider, Producer, Processing, Distribution, Retailer, Consumer) that is accessible to all the participant actors which not only enables transparency and trust also ensure the quality and safety of the Agri-product. The article presents various ongoing projects that make use of blockchain technology in their supply chain focusing on food security, food safety, food integrity, small farmer support, waste reduction, supervision, and management. The Blockchain for Zero Hunger is an ongoing project based on Ethereum that distributed digital food coupons to Palestinian refugees that focus on food security. Walmart and Kroger are companies to embrace blockchain technology into their supply chain for food safety. Downstream beer used blockchain technology to focus on food integrity that enabled customers to know everything they want to know about beer (such as its ingredients and brewing methods). OliveCoin used blockchain for the trade of olive oil, supporting the olive market by reducing the overall financial costs. AgriBlockIoT is another initiative using a blockchain-based solution for agri-food supply chain management that enables the integration of IoT devices to produce and consume digital data along the supply chain. The paper also presents various challenges and barriers to adopting blockchain technology like accessibility, governance, and sustainability, regulation. The paper concludes with the recommendation that government should lead by example to reduce the barrier of adoption of blockchain technology and fostering the digitization of the public administration.

[14] proposes a blockchain-enabled supply chain management called FARMER (FARMer And Rely) that aims to address the problems that exist in the traditional supply chain like lack of 
transparency, trust, untimely and incomplete payment for the farmer, tampering of the data, and involvement of middleman. Blockchain technology can solve the issues as it offers features like decentralization, immutability, transparency, and security. The proposed system is a web application using BigchainDB, Linux(Ubuntu), Python 3.6, and Monit) where we can establish a trustworthy value chain from farm to fork. BigchainDB is used as a database that has high throughput, low latency, powerful query functionality, decentralized control, immutable data storage, and built-in asset support. Linux(Ubuntu) is used as an operating system for easy, fast installation and setup. Python and PIP were used for the development and testing of the system. Monit to monitor and fix the errors. Fair and timely payment is ensured and the involvement of the middleman is eliminated by the smart contract that is stored in the BigchainDB. The webbased user-friendly agricultural supply chain enables greater transparency and enhanced product quality. All the actors in the supply chain from farmer to consumer can keep track of the product. This allows all the parties to be more accountable while removing the artificial inflation of the price. Also, this helps to increase customer trust and confidence in the product they consumed.s

[16] proposed a blockchain-based supply chain management system that would solve all the problems of traditional and poor supply chain management in India. The paper highlights the major problems faced by Indian farmers:(i) lack of facility to store their products, (ii) unable to monitor the product's status and sell them with profit. The proposed system is believed to provide transparency about the product's status while maintaining a good relationship between producer and consumer. The authors present the architecture of the proposed system where product information is collected from the farmers using the application before they are transported from the farmer's place and this information is verified by the smart contract. Once all the information is found correct, it is stored in the blockchain network. Different sensors (IoT agents) are placed in the storage place and vehicle to measure temperature, humidity, and presence of chemicals. All the detailed information recorded by sensors is stored in a blockchain that lets both farmers and consumers know the status of the products at various stages of the supply chain. The system also helps to track the changing market price and incorporate the current market price in the blockchain.

\subsection{Blockchain in Food Traceability}

[5] proposes a blockchain technology and IoT-based food traceability system based which is trusted and self-organized. The authors described the architecture of the proposed system that involves the traditional ERP legacy system and a new IoT system involving all parties in agribusiness. The system is a virtual blockchain network consisting of two types of nodes where one is equipped with all functionalities of blockchain node and the other is the thin node which is just a simplified payment verification (SPV) node that only verifies the payment and stores transactional data. IoT technologies eliminate human intervention by replacing manual recording and verification as possible. All actors including customers would be able to access the data stored in the system and verify them using their smart mobile phones thus increasing trust among the actors. Further authors plan to implement smart contracts that would help law executors for problem identification and timely processing.

[7] presents an overview of how blockchain technology adoption has enabled the trace of agrifood products. The author also presents a brief explanation about blockchain's architecture, smart contracts, consensus methodology, and types of blockchains. The authors discussed different existing blockchain-based frameworks in combination with IoT and smart contracts whose main aim is food safety and food security. Blockchain provides an immutable distributed ledger with an encryption mechanism to share every product's information at every stage of the supply chain with each stakeholder. The authors also highlight some of the companies who have built 
blockchain-based systems for tracking and tracing agri-food products. Some of them which are IBM Food Trust to trace the provenance of the Chinese pork products and mangoes, Provenance for tracing fish products, AgriOpenData for tracing whole agri-food, AgriDigital for improving the whole grain supply chain by making it easy, simple and secure to connect farmer and consumer. The authors also present some of the challenges for blockchain implementation despite the technology gaining more and more ground in the supply chain.

[8] discuss the application of blockchain in the safety and quality of agri-food in four aspects: data transparency, data traceability, food safety, and quality monitoring, and agriculture finance. The article also presents the case study of the Walmart pork traceability system to demonstrate the use of blockchain technology in traceability. Traditional supply chain management and interaction are unidirectional where the upstream party can only interact with the downstream party. Such systems are unreliable and inefficient where various supply chain actors do not have enough information about the product that could trace its origin in case of any food contamination or any issues. Blockchain with its immutable and decentralized nature can connect all aspects of the supply chain and records enough information at every stage from food production to food at the consumer table. All the information about the product could be accessed by all the participating parties hence increasing transparency and building trust among each other. The digital data is recorded at every stage of the supply chain, e.g. farmer, food processor, packer, distributors, and retailer. Data recorded in blockchain are immutable and accessible to all parties, which enables to trace of the products. Real-time food tracing systems based on blockchain technology provides an information platform that allows all supply chain members to access all information connected with a specific food item, enabling food supply chains openness, transparency, neutrality, dependability, and security. Blockchain records every information about the product at every stage like the number of pesticides, artificial colorants, food chemicals, appearance, temperature, humidity, light gas that are essential to monitoring the product safety and quality. For agricultural financial services, blockchain technology can provide quick and real-time payments, lowering the transactional costs that increase cash flow and working capital. Blockchain enables low-cost, quick, and secure payments that eliminate the burden on farmers. The payments can be done within few minutes with very few transaction fees without the involvement of any middle agents like remittances or banks. Hence blockchain enables efficient agricultural financial transactions with an enhanced supply chain.

\subsection{Blockchain in Farmer Direct Marketing}

[12] proposes a Blockchain-based Producer-Consumer Model(BPCM) which enables the farmer to sell their commodities directly to the consumer while preventing the inter-agents from using the smart contracts that enable the farmer to gain more profit. The author also examines the blockchain features along with their application and discusses the benefit of farmer's direct marketing. In the traditional producer-consumer model, the farmer or producer has to sell their Agri-product to the middleman and the middleman sells the same to the consumer by increasing the price. Here inter-agents get more benefit as farmers have no control in setting the price. The proposed BPCM is developed using Ethereum, a public blockchain where farmers and consumers are provided with a unique identity and all are connected to the blockchain network. The nodes willing to join the BPCM have to prove their identity using Proof of Work (PoW) consensus where nodes will not be added to the network if the node fails to prove its identity. The model restricts the transactions between the consumer's nodes that will not allow any inter-agent who intend to pretend the consumers using the smart contract. Here the consumers can buy the products directly from the farmer at a reasonable price. The transaction can be initiated by either producer(farmer) or the consumer with their identity that creates the block for the transaction. The newly created block is then broadcasted in the network to all the nodes for validation. The 
smart contract is used for the validation of the transaction where it checks whether the transaction is requested between the farmer nodes and consumer nodes or between the consumer nodes. If the transaction is between farmer node and consumer nodes, the smart contract will execute the transaction as valid. The transaction request from consumer node to consumer node is blocked allowing the farmer to sell their products to ' $n$ ' consumers while restricting the middleman in the identity of the customer to earn the profit. The Proof of Work (PoW) consensus algorithm is used to ensure that all the nodes in the BPCM agree to the transaction. Lastly, when the transaction is confirmed the block is added to the chain where the transaction gets executed. The blockchain ledger is updated with new transactions and each node maintains a copy of the transaction. In this model, the transaction is not confirmed if (1) the node failed to prove its identity and (2) the transaction initiated is between the customer nodes. The proposed model serves as a unique model where farmers directly can sell their product to consumers where they have control over the price and consumers also get the product at a reasonable price while maintaining a direct relationship with the farmer.

\subsection{Blockchain in Simplifying Transaction}

[17] propose a blockchain-based IoT system that simplifies the buying and selling of crops and land by storing the sensor data in a blockchain and deploying the smart contract build on the Ethereum blockchain. The system enables transaction peer-to-peer and smart contracts that execute automatically when specified conditions are met. All the sensor data and transactional information can be recorded in the blockchain permanently that enables a farmer can get realtime data on seed quality, climate-related data, payments. soil moisture, demand, and sale price all in a single platform. In the proposed system, different sensors like the temperature sensor, humidity sensor, moisture sensor, and $\mathrm{pH}$ sensor are connected to the Raspberry pi model 3B. The smart contract is written in Solidity language. Its front end is developed in HTML and Angular JS and deployed in a test network called Ganache. Smart contracts enable a secure and fast method of payment for buying and selling. For deploying blockchain. Node.js and Truffle framework is used while for initiating transaction a browser extension called Metamask is used. When a retailer wishes to buy crops, he can log in to his account and initiate a transaction using his private key as the signature. The data and time of the request along with the transaction are recorded in the blockchain. When the farmer receives the request, he provides the requested product and keeps track of the temperature, humidity, $\mathrm{pH}$ of the soil, and moisture content. The date and time of the request are stored together with the transaction using his private key. Once the smart contract's requirements are satisfied like the buyer received the crops, the money or ether, in this case, is deposited automatically in the seller's account which eliminates the involvement of the middleman. Any transaction or data update will be stored in the blockchain as independent blocks. Farmer store all the details of their crops that are available to who wants to know its history before buying it. The farmer can access the instant data about the crops that will help to make a well-informed decision while data recorded in the blockchain make the supply chain transparent and efficient. The smart contract simplifies the transaction between buyer and seller making payment without the involvement of a middleman.

\section{BlockChain APPROACHeS IN Agriculture}

The use of blockchain technology in agriculture is growing which leads to the development of a blockchain-based system where agribusiness activities can be executed. We selected six start-up companies that have implemented the blockchain-based solution in agriculture as case studies to examine the application and benefits of adopting blockchain technology. There were no precise 
criteria for selecting the cases other than that they have implemented the blockchain-based solution in agriculture. We gathered additional data from internet sources like industry journals, blogs, news stores, and company websites as well as scholarly and practitioner literature on innovation management and food business. We focused on the information about how blockchain technology was implemented to address various issues in agriculture. Table 2 highlights some of the insights of the cases we selected. Table 3 summarize our findings.

Case 1- AgriDigital -: The AgriDigital platform is an integrated commodities management solution for the global grains industry that uses the Ethereum blockchain to promote transparency and efficiency, restoring farmer trust in the ecosystem [18].AgriDigital is the world's first settlement of an agricultural commodity on a blockchain which enables real-time payment removing the counterparty risk for the seller[18]. AgriDigital aims to make the global supply chain simple, easy, and secure. Agridital software is flexible, simple, and easy to use. AgriDigital is a web-based platform that may be accessed from a computer, tablet, or smartphone. The platform is composed of five core modules[10],[19]: Transactions: This module allows the farmer and stakeholder to buy and sell the goods easily by handling all components of buying, selling, and logistics. Storage: All the information including payments, orders, deliveries, inventory, and confidential information are stored digitally in this module. Connections: Farmer and costumer can expand their connection using this module. Finance: This allows execution of all financial transactions and transfer of virtual currency(token) between farmers and consumers. Remit: The remittances issued to the farmer are automatically transferred.

Blockchain technology was used in removing counterparty risk for sellers through real-time payment, automating and democratizing access to supply chain financing for buyers, and guaranteeing that all consumers have access to the provenance of their commodities to make informed purchase decisions[20].The platform records all the critical data about farming, production, transportation, and delivery of products on the cloud enabling it to address food fraud and security the in global supply chain. Farmer gets notification of each move like when their crops are delivered on the site to a buyer, or payment of invoice has been complete [21]. The AgriDigital created the digital title to a physical commodity by developing the token. These token representing physical commodity remains in the blockchain which means immutable information could be accessed by everyone, hence creating 'digital trust' among all the participants in the supply chain.[10],[22].

Being the world's first company to executed live-ever settlement of the physical product on the blockchain between grower and a buyer, Agridigital now has 300 active users and is operating in 30 countries. From the pilot project that were successfully executed, the main contribution of Agridigital in agribusiness can be summarized as: [23],[24][25]

- provides an opportunity to connect the local farmers to the global supply chain.

- tracking of real-time data (location, status of the assets at any given time) of a grain sale between grower and the buyer for transparent supply chain.

- execution of the real-time payment settlement via smart contract, that that help to eliminates the counterparty or credit risk to the grower where it ideally would take two to five weeks for payment in Australian grains industry.

- offering customers with comprehensive trade flow management, access to funding and traceability of the item's origins

- provides AgriDigital users with full scale trade flow management, access to finance and traceability of the item's origin. 
Case 2- TE-FOOD: TE-FOOD is a public permissioned blockchain-based farm-to-table food traceability system that enables all supply chain participants and the customer to trace the food's information. The FoodChain (TE-FOOD's blockchain) is a public permissioned blockchain that allows supply chain actors and consumers to maintain master nodes to decentralize traceability information. Customers of TE-FOOD have the flexibility to gain in-depth insights into the food industry's supply chain. TFD is TE-ERC20 FOOD's token, which is mostly used on the Ethereum platform. Its mission is to offer transparency in the food supply chain by monitoring the items through the whole supply chain (farm, processors or slaughterhouse, distributor, retailer) and providing tools to customers, supply chain firms, and government agencies to learn about food history and quality. The TE-FOOD aims to increase consumer trust and brand exposure, obtain greater supply chain knowledge to improve operational efficiency, comply with export rules, protect their brands from counterfeiting, and execute faster product recalls [26]. TE-Food system comprises of [27]: Identification Tools: It includes 1D/2D barcodes/RFID ear tags, security seals. and label stickers. Traceability tools: It consists of a B2B traceability administration mobile app, web app, central system, external interfaces, and reporting tools. Retail and consumer tools include B2C fresh produce history insight mobile app, and web app, retail side food history digital signage tools. National livestock management solutions: It consists of livestock administration and enforcement systems. Farm management tools: These tools are based upon the category-specific (Vaccination, feeding, fertilizers, plant protection products, etc.). Food safety tools: These tools include a Fraud management system, Food condition sensor equipment, Meat quality visual analysis system.

To identify the tracked physical objects (products, locations, etc), the system implements different identifications materials: plastic seals with QR codes, plastic identification tags with $R F I D$, and paper-based label sticker with $Q R$ codes). For traceability, it provides different client applications: mobile app used by $\mathrm{B} 2 \mathrm{~B}$ and customer to scan identification materials and request/enter data, Web App for the customer who does not use the mobile app to access the product history, IoT API for food companies that enable to combine information received from the sensors and Open Interface for supply chain companies who use software already to handle product's information [28].TE-FOOD offers two implementation models, private or institutional. In Private implementation, a system is used to trace their activities while in Institutional implementation, authorities or public government, the system is used to trace a group of companies(geographically or industry category related). TE-FOOD comes with the full package of tools and applications needed for the whole supply chain to implement food traceability by end-to-end operational visibility and process control.

TE-FOOD being focused on food trackability, provides unique solutions in agricultural industry:

- It is only the trackability solution that offers different services B2B(Business-toBusiness), B2C(Business-to-Consumer) and B2A (Business-to-Authorities), benefiting businesses, consumers and authorities.

- It builds consumer trust as they are able to track the origin of the food product including all processing the product underwent.

- Due to proper trackability facility and IoT sensors, the food product that are contaminated can be quarantined at early stage before it reaches to retailer, reducing various foodborne illness.

- Regulatory bodies have real-time perspective of the food market that help to improve food safety regulatory monitoring and enforcement.

One of the limitation TE-FOOD is that TFD token that runs on the Ethereum network has low transaction/second(15 TPS) which is relatively slow. Similarly TE-FOOD has to face an direct and indirect competition form different rivals companies like: AMbrosus, WABI, MOD, WTC. 
Also TE-FOOD having large numbers of customers in Hungary and Vietnam, it is struggling to get exposure in international market.

Case 3- Etherisc: It is an open-source development platform that focuses on building decentralized crop insurance applications. Etherisc builds decentralized, blockchain-centric applications for different sectors of the insurance industry. Etherisc's blockchain crop insurance solution has been successfully tested in a Srilanka in collaboration with Aon and Oxfam to lower risk and cover the risk effectively, in 2019. In November 2020, Etherisc has announced to team up with Chainlink to deliver crop insurance in Kenya whose objective is to trigger insurance payouts automatically in case of extreme weather events. [29],[30]. Ethernet's crop insurance solution is developed on Etherisc's Etherium based "Generic Insurance Framework" that uses local metrological parameters as an input to the smart contract. The decentralized oracle network of Chainlink provides a secure and reliable end-to-end connection to different external weather data sources and broadcast the data to the smart contracts for all the parties so they can verify the information independently.

In the case of extreme weather events, insurance policies are triggered automatically by the input data which result in fair, timely, and transparent payouts where an insurer is not able to tamper or alter. [31],[32]. Users may choose their agricultural product and field location in the Crop Insurance Application, then apply for insurance by paying Ether to a DAPP (aka "smart contract"). They receive an automatic, immediate payout in the event of a drought or flood. Algorithms in the smart contract automatically check GPS and weather station data depending on the location of the farmer's fields, which allows Etherisc to assess risk and contract conditions cost-effectively at the outset and handle claims over time. The insurer saves time and money by eliminating a labour-intensive procedure. The risk of human error is also reduced through automation. This can cut down on fraud while also making claim payouts more efficient[33].

Being crop insurance company based on blockchain technology, it has positive impact in agriculture industry:

- Instant payment are triggered based on the weather data without making farmer to claim, removing a time consuming and labour intensive task that not only make farmer easy but also adds transparency.

- Automatic trigger of insurance policy with weather data as input mitigates the risk of human errors and risk of human frauds at the time of pay-out.

Some of the challenges/issues that faced by Etherisc crop insurance solution are:

- Basis risk caused by poorly designed goods, distance between index measuring site and the actual production field and size and unpredictability of the region covered;

- Risk of tampering of data of the weather station used for index calculations for benefit the companies involved.

- Shortage of adequate weather station and data affect the successful implementation of weather based crop insurance solution.

Case 4- AgriLedger: AgriLedger is a social entrepreneurship initiative for agricultural farmers that uses distributed ledger technology and mobile applications. It is a mobile application build on R3's Corda (blockchain platform) that provides a comprehensive set of integrated services to all the participants in the supply chain building trust among each other. In 2019, AgriLedger launched a blockchain ecosystem for Haitian farmers to increase supply chain transparency and promote more equitable product pricing for suppliers and retailers. The mission of AgriLedger is 
to empower small farmers by making easy processes to access the global market via the mobile platform and financial services via API links with local banks and financial institutions. The application mainly focuses on traceability and payment that will allow the producer to retain ownership until the final sale. Blockchain technology is used to record and verify, payment and money transfer, digital identity, and smart contracting[34].

AgriLedger is a blockchain-based mobile application for simplifying the transaction in the supply chain which includes the following features[35]: Digital Identity: Each actor in the supply chain including the farmer gets a unique digital identification number once they create a profile by registering with key information. This allows each farmer to be recognized as a significant factor in the supply chain, giving them improved access to financial, insurance, logistical, and other services. Asset Digitization: Assets (such as rice or coffee) can be digitized through tokenization, which provides liquidity, facilitates peer-to-peer trading, and boosts the value of agricultural commodities markets by participants of all players of the supply chain. Immutable Data: The information stored on the distributed ledger technology is immutable, creating trust, transparency, and traceability throughout the complete supply chain. Record Keeping and Access to Financial Services: The digital ledger created provides better record-keeping and proof of income that help farmers access finance loans and other financial services. Digital Wallet: The digital wallet facilities the farmer in applying and receiving a direct deposit from the financial institution. Also, implementation of financial transaction from buyer to farmer allows the farmer to receive payment for their products faster and enhance supply chain efficiency.

Here is how Agriledger simplifies the access of farmers to the global market. For instance: A farmer from Haiti drops off 500 mangoes at a collection point, where they are counted. Those 500 mangoes are registered (digitally) in the farmer's name in blockchain(say block1). Those mangoes from the collection point are delivered to Port-au-Prince(Haiti's capital) and are delivered to the US (say block 2). After a week, they arrived in the US(say block 3) and those mangoes were sold to the supermarket on the next day (say block 4). Here customers can learn how those mangoes were delivered by scanning the QR code sticker. On the other hand, farmers get notified by sending SMS when the mangoes are sold at the destination market. With AgriLedger, every farmer, supplier, Agri-product, receives a unique ID or QR code sticker that must be processed at each stage of the way. The person holding the scanner may only add data to the distributed ledger, and their ID is recorded each time they do so. This way digital information is recorded at every stage of the supply chain that can be trusted by everyone in the chain. With trustworthy data stored in an immutable distributed ledger has enabled the rural farmer(in Haiti) in making educated decisions, demonstrate financial stability, and go to the bank and obtain a loan[36].

Specially small farmer in poor and developing countries are benefited from the AgriLedger in number of ways[37][38]:

- Provide accurate and verifiable record keeping for farmers that help to get fair and faster payment after sales.

- Reduce the cost of production by sharing of resources, collective buying power of products and processes.

- Digital identity to small farmer open opportunity to reach financial services (banking, microfinances and loans) that boost farmer's income by $50 \%$, that can help to solve problem of unbanked farmer.

- AgriLedger opens door to global agriculture market for the small farmer who are struggling to reach even locally. 
AgriLedger besides its huge economic impact on farmer's living, it struggle with some issues such as[38]:

- Security of the farmer's private key, which in case someone got access to it they could perform unauthorized transactions.

- Application inappropriate for the farmers who are illiterate, especially in developing country.

- Infrastructure issues like electricity for mobile charging, internet accessibility and network cover in remote areas.

Case 5-Ripe.io: Ripe.io, an American company founded in 2017, is involved in developing innovative methods of tracking food using blockchain technology through "Blockchain of Food". The "Blockchain of Food" is a food tracking network that aims to provide information about the origin of the food, its growing circumstances, how it was delivered and other food data that might be of interest to consumers build by using blockchain technology, IoT, AI and machine learning [39].Ripe.io is collaborated with R3's Corda (blockchain platform) to build its solution to improve transparency and trust in the food agricultural supply chain[40].Ripe.io currently is offered as software-as-a-service but in long run, it will evolve into a fully licensed API and transactional product.

The goal of ripe.io is to reconnect the supply chain by telling the story of a product by promoting transparency along the entirety of the supply chain and assembling the histories of products as they move. The system comprises a software stack that includes a blockchain, on top of which a hardware solution may plugin and upload data as needed, resulting in a food internet powered by sensors. The system offers an architecture for data collection in the food supply chain, recording it in a blockchain ledger, sharing it with others in the supply chain, and validating it while maintaining data privacy and security [41]. Blockchain technology is used to facilitate the exchange of information with all the actors in the supply chain and hence validating the quality of food as it moves along the chain. Using blockchain and IoT, it was possible to monitor every aspect like temperature, humidity, and colour while storing the data digitally and securely [42]. A sensor or sensor set gathers data on a collection of variables that are hypothesized or proved to be important to that actor at each step of the product's life cycle. The collected data is uploaded automatically to the blockchain without human interference eliminating the risk of human errors. Data is in real-time and can be accessed by mobile application or from the desktop experience. Dataset gathered and uploaded in the blockchain by different sensors across the lifespan of the product, that includes a history of circumstances the product has encountered, can be analysed and shared as required to improve the entire supply chain [43].

The primary impact of ripe.io in the agriculture industry can be summarized as [42]:

- Empower customer by giving access to information about the origin and producing conditions of the crop.

- Facilitating farmer as they can record and monitor the information like temperature, humidity, light, $\mathrm{PH}$ value, from the sensors that are important for quality crop production.

- Quality level of the crop is recorded and can be accessed by all the parties in the supply chain to ensure food safety and security.

Ripe.io aiming to reconnecting the supply chain by use of blockchain technology and IoT sensors faces some of the challenges such as[44]: 
- Performance issues as IoT devices that stream continuous data could cause performance issues as blockchain throughput is limited due to its complex cryptographic security protocol.

- Lack of trust and adoption on blockchain technology as it is very new and is still immature.

- Interoperability issues from legacy system to new blockchain technology with extra cost and expertise.

Case 6-AgUnity: AgUnity is a blockchain-based smartphone app that helps small farmers in planning, trading, and tracking their daily transactions. It is built on a Multichain blockchain platform that enables to connects farmers with buyers, enhances transparency, and provides them the money they need to succeed in a global market. [45]. AgUnity aims to improve enhance farmer's economic condition and overall negotiating power with the use of blockchain and smartphone solutions, reducing food waste and farmer inefficiencies. So far AgUnity has initiated two pilots projects in Kenya and Bougainville [46].

The AgUnity Mobile App focuses on six key functions [46],[47]: Planning: Helps farmers in determining when crops are ripe for harvest or when equipment is required. It also makes it easier for cooperatives to share information and plan. Tracing: Records every step of the supply chain, and tracks it down to the farmer. Buyers pay a premium for quality assurance and ethical traceability that can boos crop value by more than 50\%. Processing: Help to increase trust in every stage of the process from field to market as they can get insight into their goods being processed or sold in real-time. Transfer: Replace the paper records with secure phone-to-phone QR code transactions stored in the blockchain which helps to avoid misunderstandings and disagreements. Market: Exposes the farmers to the various agricultural market where they could buy high-quality products like multipurpose solar kits. Wallet: Serve as a micro-finance system for the farmer. Payments from crop sales arrive in farmer's wallets almost instantly, allowing them to withdraw money from the co-operative or make a purchase via the app.

Farmers are given cell phones pre-loaded with the AgUnity software, guaranteeing that they use program-compatible technology and secure devices while accessing the AgUnity blockchain [48]. In remote regions, the app can work without an internet connection until one is created. The app with a customizable pictographic interface enables the integration of different crops types and cultural peculiarities into the platform [47]. The use of a blockchain made it easier to convey to the farmers that if both parties agree on a transaction, no one, including the farmer, the cooperative, or even AgUnity, can ever alter the records. This feature of blockchain also adds an extra layer of protection to guarantee that these transactions are not hacked by third parties who want to transfer receipts from the farmers to themselves. Farmers are given a free smartphone with the AgUnity application loaded in addition to other basic applications such as Google Maps, YouTube, and Facebook, which assists farmers to become more effective via planning and collaboration. These phones are designed especially for the low-literate farmers with a simple user interface where farmers cannot download any other application on the phone. Farmer retains the ownership for all the data collected by the farmer using the application [46],[47],[48]. Farmer logs on to the application to keep track of crop processing and sales. All the members can visualize the transactions, ensuring that all parties follow through on agreements. Each farmer is assigned a digital wallet to hold receipts, which are subsequently converted to cash at the cooperative. Farmer can also communicate on harvest planning and equipment sharing using AgUnity's encrypted messaging services [47]. It is observed that farmer increased income by three times within one season using the AgUnity's application in Kenya, that enable cooperation and trust.

The major benefits AgUnity's implementation can be highlighted as [49]: 
- Smartphones provided for farmer with inbuilt application play major role in storing and maintain immutable records enabling trust among every parties.

- Instant payment debited on farmer's wallet app that can be used to make purchase provide easy access to wider agricultural market.

- Paperless transaction based on blockchain mitigates the risk of fraud and disagreements.

Table 2. List of blockchain-based companies and insights

\begin{tabular}{|c|c|c|c|c|}
\hline S.N & Case & Insight 1 & Insight 2 & Insight 3 \\
\hline 1 & AgriDigital & $\begin{array}{l}\text { The world's first } \\
\text { blockchain-based } \\
\text { agricultural } \\
\text { commodities } \\
\text { settlement }\end{array}$ & $\begin{array}{l}\text { Remove counterparty } \\
\text { risk for sellers through } \\
\text { real-time payment }\end{array}$ & $\begin{array}{l}\text { Creates the 'digital } \\
\text { title' to a physical } \\
\text { commodity by } \\
\text { developing the token. }\end{array}$ \\
\hline 2 & TE-Food & $\begin{array}{l}\text { Provides greater } \\
\text { food traceability }\end{array}$ & $\begin{array}{l}\text { Increase consumer } \\
\text { trust and brand } \\
\text { exposure and obtain } \\
\text { greater supply chain } \\
\text { knowledge }\end{array}$ & $\begin{array}{l}\text { Offer two } \\
\text { implementation model: } \\
\text { private and } \\
\text { institutional }\end{array}$ \\
\hline 3 & Esterisc & $\begin{array}{l}\text { Offer blockchain- } \\
\text { based crop } \\
\text { insurance solution } \\
\text { to lower risk and } \\
\text { cover the risk } \\
\text { effectively }\end{array}$ & $\begin{array}{l}\text { Insurance policies are } \\
\text { triggered } \\
\text { automatically, enabling } \\
\text { the farmer to receive } \\
\text { automatic, immediate } \\
\text { payout in case of } \\
\text { extreme events }\end{array}$ & $\begin{array}{l}\text { Enables to cut down } \\
\text { on fraud while also } \\
\text { making claim payouts } \\
\text { more efficient }\end{array}$ \\
\hline 4 & AgriLedger & $\begin{array}{l}\text { Focus on } \\
\text { traceability of } \\
\text { products and } \\
\text { payment that will } \\
\text { allow the producer } \\
\text { to retain ownership } \\
\text { until the final sale }\end{array}$ & $\begin{array}{l}\text { Digital wallet } \\
\text { facilitates farmer in } \\
\text { applying and receiving } \\
\text { direct deposit from the } \\
\text { financial institution. }\end{array}$ & $\begin{array}{l}\text { Asset Digitization } \\
\text { through tokenization } \\
\text { facilitates liquidity and } \\
\text { peer-to-peer trading. }\end{array}$ \\
\hline 5 & Ripe.io & $\begin{array}{l}\text { 'Blockchain of } \\
\text { Food', a food } \\
\text { tracking network to } \\
\text { tack the food origin } \\
\text { and growing } \\
\text { circumstances. }\end{array}$ & $\begin{array}{l}\text { Integrate with IoT to } \\
\text { capture the real-time } \\
\text { data like temperature, } \\
\text { humidity and other } \\
\text { meta-data. }\end{array}$ & $\begin{array}{l}\text { Data stored in } \\
\text { blockchain on every } \\
\text { move can be analysed } \\
\text { and shared to improve } \\
\text { supply chain. }\end{array}$ \\
\hline 6 & AgUnity & $\begin{array}{l}\text { Smartphone app } \\
\text { that helps small } \\
\text { farmers in } \\
\text { planning, trading, } \\
\text { and tracking their } \\
\text { daily transactions. }\end{array}$ & $\begin{array}{l}\text { Farmer are exposed to } \\
\text { wide variety } \\
\text { agricultural market. }\end{array}$ & $\begin{array}{l}\text { AgUnity 'Wallet' } \\
\text { serves as micro- } \\
\text { finance system. }\end{array}$ \\
\hline
\end{tabular}


Table 3: Technical Implementation of the cases

\begin{tabular}{|c|c|c|c|}
\hline Cases & Platform & Application & Objective \\
\hline AgriDigital & Ethereum & Web Application & $\begin{array}{c}\text { Financial, Supervision and } \\
\text { Management }\end{array}$ \\
\hline TE-FOOD & Hyperledger & $\begin{array}{c}\text { Mobile } \\
\text { Application }\end{array}$ & Traceability \\
\hline Esterisc & Ethereum & Web Application & Crop Insurance \\
\hline AgriLedger & R3 Corda & $\begin{array}{c}\text { Mobile } \\
\text { Application } \\
\text { Mobile/Desktop } \\
\text { Application } \\
\text { Mobile } \\
\text { Application }\end{array}$ & Traceability \\
\hline Ripe.io & R3 Corda & Multichain & \multicolumn{2}{|c|}{ Small Farmer Support } \\
\hline AgUnity & \multicolumn{2}{|c|}{} \\
\hline
\end{tabular}

\section{DISCUSSION}

Literature review and case study about the initiative implementing the blockchain technology reveal that it would solve the existing problem seen in the traditional and typical agriculture supply chain. Many pilot projects have been launched all around the globe that aims to address the current problems seen in the agriculture industry. Blockchain as a distributed ledger where information once recorded is impossible to alter would be a perfect solution for a transparent agricultural supply chain enabling information tracing, food safety, and quality. Blockchain along with IoT and another real-time tracking system can provide a solution for an efficient supply chain where every actor can trust each other; solve the long-waiting and complex problem of payments; eliminate the middlemen who manipulate the market; ensure the product's safety and security and ultimately customer consume the product with trust and confidence. Study shows that much of the agricultural sectors are using or planning to use permissioned blockchain( R3 Corda, Multichain, Hyperledger) as it is flexible enough to allow companies to modify the ledger's rules at their choice, allowing for the cheaper transaction, better privacy and reducing the risk of traditional consensus-based assaults[50]. Experts believe that permissioned blockchain lacks the property of trustless and publicly open so in near future, the trend would shift from permissioned to permissionless blockchain with the maturity of the technology. The current trend of blockchain adoption has shifted from non-adoption to planning and exploration of alternatives and early-stage adoption.

Some of the challenges faced by blockchain for its adoption in the agriculture industry are[50]: Technological immaturity: Both permissioned and permissionless blockchain technology are considered as infant technology because it is technically immature, has regulatory risks, and lack well-defined business models; Security: Despite the hashing system that makes blockchain nothackable like centralized system, permissionless blockchain still has the possibility of $51 \%$ attack, hard forks, and system bugs. Similarly, issues like fraud risk, centralized control, data tempering danger, and lack of consensus mechanism in permissioned blockchain are challenges for adoption. Data Privacy: As a distributed ledger, information is shared among peers that create the concern of data privacy and confidentiality in both permissioned and permissionless blockchain. There are no clear regulations about the purpose of data collection and processing, what to agree, to whom to disclose the data, who is responsible and accountable for the data, and the legal rights in case of data misuse and violations. Cost of Technology: The investment for installation of new technology, interoperability issues across various blockchain frameworks, networks, and platforms, as well as between blockchain networks and legacy systems makes 
blockchain technology adoption more challenging. Scalability and Performance: The transactions processed per second and ability of expansion and growth (addition of nodes, storage requirements, and response time as the network grows) is a challenging issue in permissionless blockchain as compared to permissioned blockchain.

\section{CONClusion}

Blockchain technology would be a transformative technology soon in the agriculture industry that could address several issues like inefficiency in the traditional supply chain, food safety, security and quality issues, high transactional cost, market manipulation by middlemen, distrust of the consumer on the product. Some of the efforts can be seen through several initiatives around the globe. With some of the successful initial adoption of the technology in agriculture, its demand is increasing. But for blockchain to come to full fruition, issues (cost, scalability, performance, data privacy, technical maturity, security) need to be resolved. Limitation of our survey is that some of the case studies explored are very recent and ongoing experimentations. So all the analysis are based upon the early outcome and evidence available currently. Further research on large use cases and mature block-chain projects would give real picture of advantages of blockchain technology in agriculture. Also data for case analysis are collected from publicly available data like reports, news, blogs and website due to lack of first hand investigation of blockchain startups. Further research based on interviews and surveys of targeted actors would have benefited this study more.

\section{ACKNOWLEDGEMENTS}

I would like to thank everyone, who supported me to complete this article.

\section{REFERENCES}

[1] V. S. Yadav and A.R. Singh, "A systematic literature review of blockchain technology in agriculture.", In Proceedings of the International Conference on Industrial Engineering and Operations Management, pp. 973-981,July 2019.

[2] A. Kamilaris , A. Fonts and F.X. Prenafeta-Boldv́, "The rise of blockchain technology in agriculture and food supply chains". Trends in Food Science \& Technology, 91, pp. 640-652, 2019

[3] G.A. Motta, B. Tekinerdogan and I.N. Athanasiadis, "Blockchain applications in the agri-food domain: the first wave.", Frontiers in Blockchain, vol. 3, p. 6, Feb 2020.

[4] H. Xiong, T. Dalhaus, P. Wang and J. Huang, "Blockchain technology for agriculture: applications and rationale.", Frontiers in Blockchain, vol.3, p. 7, 2020.

[5] J. Lin, Z. Shen, A. Zhang and Y. Chai, "Blockchain and IoT-based food traceability for smart agriculture.", In Proceedings of the 3rd International Conference on Crowd Science and Engineering, pp. 1-6, July 2018.

[6] Y.P. Lin, J.R. Petway, J. Anthony, H. Mukhtar, S.W. Liao, C.F. Chou and Y.F. Ho, "Blockchain: The evolutionary next step for ICT e-agriculture.", Environments, vol. 4, p.50, 2017.

[7] K. Demestichas, N. Peppes, T. Alexakis and E. Adamopoulou, "Blockchain in agriculture traceability systems: a review.", Applied Sciences, vol. 10, p.4113, 2020.

[8] J. Xu, S. Guo, D. Xie and Y. Yan, "Blockchain: A new safeguard for agri-foods". Artificial Intelligence in Agriculture, vol. 4, pp.153-161, 2020.

[9] D. Gunasekera and E. Valenzuela, "Adoption of blockchain technology in the Australian grains trade: An assessment of potential economic effects". Economic Papers: A journal of applied economics and policy, vol. 39, pp. 152-161, 2020.

[10] M. Torky and A.E. Hassanein, "Integrating blockchain and the internet of things in precision agriculture: Analysis, opportunities, and challenges.", Computers and Electronics in Agriculture, p. 105476, 2020. 
International Journal of Computer Science \& Information Technology (IJCSIT) Vol 13, No 5, October 2021

[11] N. Srivastava, "WHAT IS BLOCKCHAIN TECHNOLOGY, AND HOW DOES IT WORK?",[Online].Available: https://www.blockchain-council.org/blockchain/what-is-blockchaintechnology-and-how-does-it-work/. [Accessed 1806 2021].

[12] S. Revathy and S.S. Priya, "Blockchain based Producer-Consumer Model for Farmers.",In 2020 4th International Conference on Computer, Communication and Signal Processing (ICCCSP)IEEE, pp. 1-5, September 2020.

[13] N. Kshetri, C.S. Bhusal and D. Chapagain, "BCT-AA: A survey of Blockchain Technology-based Applications in context with Agribusiness". Available at SSRN 3834004, 2021

[14] M.D. Borah, V.B. Naik, R. Patgiri , A. Bhargav., B. Phukan and S.G. Basani, "Supply chain management in agriculture using blockchain and IoT.", In Advanced applications of blockchain technology, pp. 227-242, 2020.

[15] U. Sengupta and H.M. Kim, "Meeting Changing Customer Requirements in Food and Agriculture Through the Application of Blockchain Technology.", Frontiers in Blockchain, vol.4, p.5, 2021.

[16] V. Sudha ,R. Kalaiselvi and P. Shanmughasundaram, "Blockchain based solution to improve the Supply Chain Management in Indian agriculture.”, In 2021 International Conference on Artificial Intelligence and Smart Systems (ICAIS) IEEE, pp. 1289-1292 March 2020.

[17] S. Umamaheswari,S. Sreeram, N. Kritika and D.J. Prasanth, "Biot: blockchain based IoT for agriculture.", 11th International Conference on Advanced Computing (ICoAC)IEEE, pp. 324-327 , December 2019.

[18] R. Campbel, “Australian FinTech Rivals UK in Blockchain Development.”, [Online]. Available: https://www.ccn.com/australian-fintech-rivals-uk-fintechs-blockchain-development/. [Accessed 1707 2021].

[19] AgriDigital, "What is AgriDigital?.", [Online]. Available: https://knowledgebase.agridigital.io/hc/enus/articles/226461448-What-is-AgriDigital. [Accessed 2606 2021].

[20] E. Picco, "Blockchain In Agriculture Use Case \#2: AgriDigital.," September 2019. [Online]. Available: https://www.disruptordaily.com/blockchain-in-agriculture-use-case-agridigital/. [Accessed $26062021]$.

[21] R. Groenevel, “Agridigital to create 'digital trust' in supply chains”, May 2019. [Online]. Availiable: https://www.futurefarming.com/Tools-data/Articles/2019/5/Agridigital-to-create-digital-trust-insupply-chains-424208E/. [Accessed 2606 2021].

[22] A. Barbaschow, "From farm to plate via blockchain: Solving agriculture supply chain problems one grain at a time.",[June , 2018]. [Online].Available: https://www.zdnet.com/article/from-farm-toplate-via-blockchain-solving-agriculture-supply-chain-problems-one-grain-at-a-time/. [Accessed 21 06 2021]

[23] Anon., "Entrepreneurs' Programme case study: AgriDigital.”, [October, 2020]. [Online].Available: https://www.industry.gov.au/data-and-publications/entrepreneurs-programme-case-study-agridigital. [Accessed 2908 2021].

[24] FinTech Australia, "Full Profile's AgriDigital successfully executes world's first settlement of an agricultural commodity on a blockchain.",[ December ,2016] .[Online].Available: https://www.fintechaustralia.org.au/newfull-profiles-agridigital-successfully-executes-worlds-firstsettlement-of-an-agricultural-commodity-on-a-blockchain-2/.[Accessed 0109 2021].

[25] Landing Pads, "AgriDigital - allows local Australian farmers to connect to the global supply chain.”,[Online].Availiable:https://www.austrade.gov.au/landingpads/news/case-studies/agridigitalallows-local-australian-farmers-to-connect-to-the-global-supply-chain. [Accessed 0109 2021].

[26] Crypto.com, “About TE-FOOD Price | TFD Price, USD Converter, Charts| Crypto.com.”, [Online]. Availiable : https://crypto.com/price/te-food. [Accessed 2106 2021].

[27] LaurelRetail.com, "TE-FOOD.", [Online].Available: https://laurelretail.com/loyalty-system. [Accessed 2706 2021].

[28] TE-FOOD, “Introduction of TE-FOOD's Technology.”, [Sep 2018]. [Online].Available: https://medium.com/te-food/introduction-of-te-foods-technology-732cdd90bb16. [Accessed 2706 2021].

[29] S. Youra., "TE-FOOD and the TFD Token, Food Traceability on the Blockchain.”, [May 2019]. [Online].Available:https://sean-youra.medium.com/te-food-and-the-tfd-token20c4ec89568d.[Accessed 0309 2021].

[30] EU-Startups, "TE-Food.", [Online]. Available: https://www.eu-startups.com/directory/te-food/. [Accessed 0409 2021]. 
[31] Etherisc, "Etherisc teams up with Chainlink to deliver crop insurance in Kenya", [Nov 2020]. [Online].Available: https://blog.etherisc.com/etherisc-teams-up-with-chainlink-to-deliver-cropinsurance-in-kenya-137e433c29dc, [Accessed 0107 2021]

[32] Ledger Insights, "Etherisc to develop a blockchain-based crop insurance for Kenyan farmers", [Nov, 2020].[Online].Availiable: https://www.ledgerinsights.com/etherisc-blockchain-parametric-cropinsurance-kenya-chainlink/.[Accessed 0107 2021].

[33] R. Peverelli and R. Feniks, R, "Etherisc: Decentralized insurance leveraging blockchain", .[Oct, 2017. [Online]. Availiable: https://www.digitalinsuranceagenda.com/featured-insurtechs/etheriscdecentralized-insurance-leveraging-blockchain/. [Accessed 01/07/2021].

[34] AgriLedger, “AgriLedger”.[Online].Available: https://yourstory.com/companies/agriledger/amp. [Accessed 0307 2021].

[35] AgriLedger, "AGRILEDGER- Democratizing Agriculture Data using Blockchain", [Online]. Availiable: https://aspioneer.com/agriledger-democratizing-agriculture-data-using-blockchain/. [Accessed 0307 2021].

[36] L. Wiget, "When mango farmers meet blockchain Agriledger", [May 2021]. [Online]. Available: https://atlasofthefuture.org/project/agriledger-farm-blockchain/. [Accessed 0207 2021].

[37] AgriLedger, “AgriLedger-Agriledger.”, [Online].Availaible: http://www.agriledger.io/ , [Accessed 05 09 2021].

38. M. Halat, “AgriLedger Analysis," YouTube., April 22018 [Video file]. Available: https://www.youtube.com/watch?v=NjhniFE84A0 . [Accessed 0509 2019].

[39] B. Taylor.L, "Maersk Leads Blockchain of Food Startup Ripe.io \$2.4m Seed Round", Sep, 2018.[Online]. Available: https://agfundernews.com/maersk-leads-blockchain-of-food-startupripeio-2-4m-seed-round.html. [Accessed 1007 2021].

[40] Ripe.io, "R3 and ripe.io partner to provide intelligent transparency and trust for the food and agricultural supply chain on Microsoft azure", [June,2019].[Online]. Available: https://www.ripe.io/media/2019/6/18/r3-and-ripeio-partner-to-provide-intelligent-transparency-andtrust-for-the-food-and-agricultural-supply-chain-on-microsoft-azure. [Accessed 17072021 ].

[41] iotpractitioner.com "IoT Slam Live 2017 Session: Creating the Blockchain of Food", [June 2017] [Online]. Availiable: https://iotpractitioner.com/iot-slam-live-2017-session-creating-blockchainfood/. [Accessed 1007 2021].

[42] M. Westerlund, S. Nene, S. Leminen and M. Rajahonka. "An Exploration of Blockchain-based Traceability in Food Supply Chains: On the Benefits of Distributed Digital Records from Farm to Fork. “, Technology Innovation Management Review, vol. 11, 2021.

[43] N. Jin and C. Saucier, "ripe. io: Reconnecting the Food Supply Chain.”, 2016.

[44] Uddin, M. Ashraf, A. Stranieri, I. Gondal and V. Balasubramnian . "A survey on the adoption of blockchain in iot: Challenges and solutions." Blockchain: Research and Applications, p .100006, Feb 172021.

[45] livebettercreatives.com, “AGUNITY”.[Online]. Available: https://www.livebettercreatives.com/casestudies/agusity. [Accessed 1007 2021].

[46] A. Hadzic , "Agriledger \& Agunity An Economics of Mutuality case study. Economics of Mutuality.", 2018.

[47] L. Denyes, N. Lesher, M. Martinez, H. McNutt and M. Nakhai, "Digital financial services for agriculture handbook. Digital financial services for agriculture handbook.", 2019.

[48] E. Picco, "Blockchain In Agriculture Use Case \#1: AgUnity", [Sep 2019]. [Online]. Availiable: https://www.disruptordaily.com/blockchain-in-agriculture-use-case-agunity/ , [Accessed 1107 2021].

[49] AgUnity, "Making Smartphones Relevant for the World's Poorest Farmers: An Interview with David Davies.”, [June 2021]. [Online]. Availiable: https://www.agunity.com/blog/making-smartphonesrelevant-for-the-worlds-poorest-farmers-an-interview-with-david-davies. [Accessed 05092021 ].

[50] E. Toufaily, T. Zalan and S.B. Dhaou, "A framework of blockchain technology adoption: An investigation of challenges and expected value.", Information \& Management, vol. 58, p.103444, 2021. 
International Journal of Computer Science \& Information Technology (IJCSIT) Vol 13, No 5, October 2021

\section{AUTHORS}

Chandra Sekhar Bhusal is a Master graduate from Federation University, Australia majoring in Software Engineering in the year 2020. He has also completed a Master of Computer Application (MCA) from the Visvesvaraya Technological University (VTU), India (2015). He has 1.5 years of experience in teaching. He has a total of two publications in the International Journal. His current research interests include information security, cybersecurity and blockchain technology.

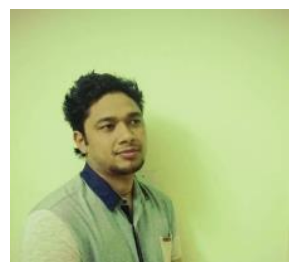

